\title{
Editorial
}

\section{Reflexión del 75 Aniversario de la Facultad de Odontología}

Este año celebramos el septuagésimo quinto aniversario de la fundación de la Facultad de Odontología. Es una magnífica oportunidad para efectuar un recorrido por estos 75 años y observar los logros que se han obtenido desde su creación.

Históricamente, es importante recordar ¿por qué nace la Escuela de Cirugía Dental de la Universidad de Costa Rica?

Después de fundada la Universidad, se da una situación a nivel nacional en la que los autorizados y los empíricos deseaban que se dispusiera una ley para ser acogidos en el Colegio de Cirujanos Dentistas, que en aquel entonces lo llamaban Facultad, nombre que no le correspondía y donde se agremiaban los cirujanos dentistas graduados. Después de muchas situaciones, el Congreso aprueba la ley, por lo que la Junta Directiva del Colegio pugnó para que el presidente la vetara.

Debido a esto, el presidente Dr. Rafael Ángel Calderón Guardia, presionado por los empíricos que querían leyes proteccionistas, los autorizados ser incorporados al Colegio y poseer un título, y por los diputados que los pretendían complacer, convocó a una reunión en la Casa Presidencial a los doctores José Joaquín Jiménez Núñez, Mariano Valenzuela, Francisco Brenes y José Aurelio Ortiz para proponerles subsanar dicha situación, exponiéndoles que si ellos se comprometían a crear la Escuela de Cirugía Dental, preparar un plan de estudios y recibir, por una única vez, a los empíricos, él vetaría la ley. Por lo tanto, así sucedió, dando vida a la Escuela de Cirugía Dental.

Este grupo de odontólogos visionarios, el presidente de la República Dr. Rafael Ángel Calderón Guardia y su secretario de Estado Luis D.Tinoco crean la nueva escuela y el 24 de diciembre de 1941 en La Gaceta N. 289 aparece el siguiente decreto ejecutivo que enuncia: "El Presidente de la República de conformidad con lo dispuesto en el inciso 5 , artículo $1^{\circ}$, capítulo VIII de la Ley Orgánica de la Universidad de Costa Rica acuerda integrar la Facultad de Cirugía Dental".

El decano, Dr. José Joaquín Jiménez Núñez y los doctores José Aurelio Ortiz Céspedes, Ricardo Jiménez Núñez, Mariano Valenzuela, Francisco Brenes y Mario Brenes conforman el grupo que inicia y quienes invitan a otros colegas a unirse a la nueva facultad.

El día 16 de marzo de 1942, a las 7 de la mañana y en el local que ocupaba la Escuela de Ingeniería, donde actualmente se encuentra la Clínica Santa Rita, inician las clases de Cirugía Dental. Este momento es histórico para la odontología en Costa Rica porque se inicia el gran aporte que hace 
nuestra facultad a la salud oral del país, donde se gestarán cambios tanto en instituciones públicas de salud como de la práctica privada.

La Facultad ha graduado 2582 odontólogos que se han ubicado en diferentes partes del país, ya sea en el Ministerio de Salud, la Caja Costarricense de Seguro Social y la práctica privada beneficiando a todas las poblaciones.

El Curso de Técnico Especializado en Asistencia Dental ha graduado 1211 técnicos, lo que ha tenido gran impacto no solo en la práctica privada sino también institucional, ha graduado, desde su creación, personal altamente calificado para colaborar no solo en asistir al profesional, sino en otras labores de apoyo a programas de salud oral que son importantes para el país.

Desde sus inicios la Facultad tuvo un plan de estudios donde se le daba importancia a la parte teórica, técnica y práctica, y también a la parte social, lo que hacía que el odontólogo graduado fuera un profesional muy bien capacitado y con una visión social muy importante, lo que vino a crear programas importantes en las instituciones para llevar la salud oral a todas las poblaciones del país, además de tener odontólogos muy bien formados para la práctica privada, la docencia y la investigación.

En 1964, la Facultad se traslada a la nueva Ciudad Universitaria Rodrigo Facio, con un edificio novedoso y con grandes facilidades para la docencia y servicios que esta ofrecía.

Se formalizó un convenio con la Facultad de Odontología de la Universidad de Michigan, con lo cual se reciben aportes de equipos y se obtiene una gran influencia en el nuevo plan de estudios.

La Facultad ha pasado por grandes cambios desde sus comienzos, siempre buscando la excelencia de los profesionales que graduamos; prueba de esto es el éxito obtenido por los que salen a efectuar estudios de posgrado. Algunos por solicitud de las mismas universidades decidieron quedarse laborando en otros países.

La carrera de Odontología fue acreditada ante el SINAES en el 2010 y reacreditada en el 2016, lo que demuestra la calidad de nuestros programas y de la eficiencia en todas sus funciones.

Este 2017 no solo cumpliremos 75 años, sino que nos trasladaremos a un edificio nuevo que cumple con todas las normas modernas de una facultad de odontología, lo que traerá grandes beneficios para estudiantes, profesores y personal administrativo.

La nueva facultad nos facilitará no solo la docencia y nuevos programas, sino que también se mejorarán los programas de externado, los campos de trabajo y toda la actividad que esta genera, beneficiando a las comunidades con diferentes programas que son impulsados por los docentes en docencia, investigación y acción social, tales como "Devuélveme la Sonrisa", "Escuela Carmen Lyra", "Ferias de la Salud", y en los cursos de odontología social a los que asisten tanto a diferentes escuelas, colegios y CEN-CINAI como a las visitas domiciliarias a personas con discapacidad. 
Hemos logrado tener una revista de alto impacto internacional (Odovtos), medio por el cual el personal académico puede publicar sus investigaciones.

El nuevo edificio nos facilitará introducir una serie de cambios en tecnología y otros con los que ya disponemos en este momento como el tomógrafo en radiología, equipos CAD/CAM, expediente electrónico y muchos otros, lo que hará que nuestra facultad siga estando a la vanguardia en la enseñanza de la Odontología.

Hemos fortalecido la educación continua con cursos y congresos como el Congreso Internacional LICIF0 donde nos esforzamos por contar con prestigiosos conferencistas. También ofrecemos pasantías y los cursos de posgrado para todos los odontólogos.

Para mi como decano es un orgullo poder estar al frente de la Facultad en un año tan importante para todos.

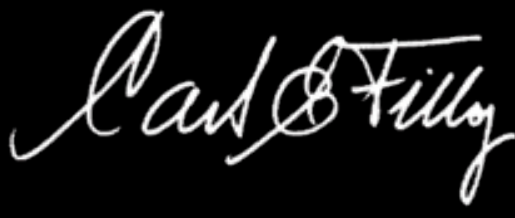

Dr. Carlos E. Filloy Esna ${ }^{1}$

1. Decano, Facultad de Odontología, Universidad de Costa Rica, Costa Rica.

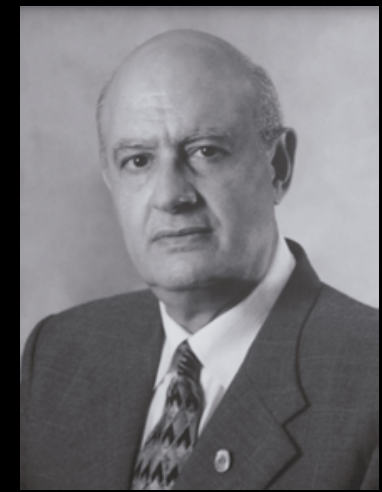
use. (NC) You may not use the material for commercial purposes. 